\title{
Investigation of transverse residual stresses in a thick pultruded composite using digital image correlation with hole drilling
}

\author{
Onur Yuksel ${ }^{1,2, *}$, Ismet Baran ${ }^{1}$, Nuri Ersoy ${ }^{2,3}$ and Remko Akkerman ${ }^{1}$ \\ ${ }^{1}$ University of Twente, Faculty of Engineering Technology, NL-7500AE Enschede, The Netherlands \\ ${ }^{2}$ Department of Mechanical Engineering, Bogazici University, Bebek, 34342, Istanbul, Turkey \\ ${ }^{3}$ Department of Engineering, Design, and Mathematics, University of the West of England, BS16 $1 Q Y$, \\ Bristol, United Kingdom \\ ${ }^{*}$ E-mail: o.yuksel@utwente.nl
}

\begin{abstract}
Process induced residual stresses are one of the main sources of defects such as (pre)mature matrix cracking during pultrusion of fiber reinforced polymer composite profiles. Recently, comprehensive process models have been developed to understand and describe the underlying mechanisms of the residual stresses in pultrusion processes. The predicted stresses however have not been validated with experimental measurements which are necessary to verify the implemented material models and assumptions in the process models. A hole drilling method with digital image correlation (DIC) is used in the present work to measure the transverse strain relaxation due to material removal in a pultruded thick composite profile $(20 \times 20 \mathrm{~mm})$ made of unidirectional glass/polyester. The corresponding residual stress state is back calculated using the measured strains in a finite element based numerical model. The estimated level of transverse residual stress in the core of the profile was found to be 6.1 MPa in tension.
\end{abstract}

Keywords: Digital image correlation (DIC); B. Residual/internal stress; C. Finite element analysis (FEA) ; E. Pultrusion; Hole drilling

\section{Introduction}

Pultrusion is one of the most commonly used continuous manufacturing techniques for constant cross sectional fiber reinforced polymer composites (FRPCs). It can consist of uniPreprint submitted to Composite Structures

April 14, 2019 
directional (UD) roving, continuous filament mat (CFM), stitched fabric and woven fabric reinforcement [1]. Pultrusion can be performed in different ways. Most common types of pultrusion are resin bath pultrusion and resin injection pultrusion [2-4], which are shown schematically in Fig. 1. Pultruded profiles are widely used in various industries such as wind energy, transportation and construction since they have a relatively high fiber volume content with consistent mechanical properties. An example is the blade root reinforcement of a wind turbine blade made of UD thermosetting pultruded profiles.

One of the main sources of defects as (pre)mature matrix cracking, encountered in the pultrusion, is residual stress locked in the structure. Residual stresses and shape distortions, the latter being the consequence of the former, are formed in the structure during the process. The physical reasons for the transverse residual stresses in pultrusion are outside to inside curing, non-uniform curing as well as heating/cooling, and nonuniform fiber distribution which result in non-uniform material property evolution through the thickness $[5,6]$. Due to the peripheral heating with the pultrusion die, the curing in the center of the pultruded profile starts later than the outside regions and continues even after the die exit which causes outside to inside curing. This means that after outer regions are cured and vitrified, the center of the profile continues to shrink during curing and this phenomenon ends up with tensile residual stresses in the core region transverse to the pulling direction. Premature or visible matrix cracking might occur depending on the residual stresses in the matrix material. These residual stresses have been studied for various pultruded profiles in [7-12] by using numerical thermo-chemical-mechanical process models. Table 1 provides an overview of the predicted residual transverse stresses together with the processing conditions presented in [7-12]. It is seen that the residual stress level was found to be in the range of $0.26-10.7 \mathrm{MPa}$ at the center of the profiles analysed, depending on the resin material, the fiber reinforcement, thickness of the profile and process conditions. One of the recent studies on pultrusion showed that tensile strength in the transverse direction of the web part of an I beam pultruded profile was around $47 \mathrm{MPa}$ [13]. Therefore the residual stresses in the predicted order of magnitudes may be critical during in-service loading, hence the 
predictions obtained from dedicated process models need to be validated with experimental findings. Apart from residual stresses, the predictions for the process induced shape distortions were extensively studied and validated experimentally, by e.g. spring-in, spring-back and warpage $[10,14,15]$.

The residual stresses were analyzed experimentally for FRPCs by using different techniques such as the layer removal method [16], the hole drilling method [17, 18], deep hole drilling technique $[19,20]$, the contour method [21], the first ply failure method [22], the radial cutting method [23] and the matrix removal methods [24]. These techniques have been employed mainly to measure the in-plane residual stresses in continuous FRPCs. Of these techniques, the hole drilling method is particularly suitable to measure also through thickness residual stresses for large and thick section components.

Measuring internal stress with hole drilling is common for various materials. It is traditionally employed with strain gauges based on ASTM standard E837 [25]. It was firstly proposed in 1940's and developed for isotropic materials [26]. Then, several studies on residual stress measurements with this method were published for orthotropic materials and composites [17, 27-30]. Quantitative estimations of the residual stresses are derived from the data obtained with a strain gauge rosette which has a diameter, which is passing through the middle of the gauges, typically 2 or 2.76 times larger than the suggested hole diameter [25]. Each strain gauge in the rosette types suggested by the ASTM standard[25] covers an area varying between $0.62-10.1 \mathrm{~mm}^{2}$ and gives an average value for the strain under that area. Therefore, an average strain under the gauge has to be analyzed which is one of the limitation of the strain gauge measurements[31]. On the other hand, most of these problems can be overcome with full field optical methods which can be subdivided into interferometric techniques and non-interferometric techniques. The former such as Moiré, holographic, speckle and electronic speckle pattern interferometry and shearography mostly provide higher sensitivity and accuracy [32]. However, they are highly sensitive to vibrations and need to be conducted in a well-controlled environment. On the other hand, the non- 
interferometric techniques are simply based on image processing in which the deformation patterns are captured with standard cameras. The Digital Image Correlation (DIC) is one of the most commonly used non-interferometric optical techniques. Its ease of application and flexibility make it popular in recent years [33-35].

The hole drilling technique in combination with DIC has been employed in several studies [36-40]. Numerical parameters such as subset size, step size and region of interest are common concerns for the DIC measurements due to the use of numerical correlation between captured images to handle displacement data [41]. For the sake of clarity, it should be noted that different names were used in literature for the unit pixel area of DIC algorithm. Some of these names are facet [42], block [40], patch [38] and mostly subset [36, 41] which was also preferred in this study. Apart from the DIC parameters, the speckle quality is also important for the accuracy of the measurements. In [33], DIC was used to capture the micro-scale strain field through the transverse direction of fibre reinforced material and the speckling would be possible with alumina suspension. An optimization process for the preparation of the suspensions was carried out and the quality of speckle pattern was evaluated with strain deviation analysis. Uncertainty analysis was performed in [34] for the material property characterization of composite materials with finite element updating. It was suggested that an optimum region of interest (ROI) can be determined and more data used to identify the material properties lead to a smaller standard deviation (STD) and coefficient of variation (COV). It is noteworthy that the sensitivity of DIC depends on optical conditions, strain field and the post-processing parameters. In [40], a problem-specific shape function was suggested to increase the accuracy of the DIC and this approach was validated with mechanical tests. In [38], stresses were measured for the four different structural element types as I-beam, square tube etc., however the proposed method still needs a calibration. The residual stress state in a neat epoxy was investigated in [36] using hole drilling with DIC. The measured strain field was used for the analytical residual stress calculations and the stress level was found to be approximately $5 \mathrm{MPa}$. Table 2 presents an overview of the studies which used hole drilling with DIC for the residual stress characterization, showing 
that hole drilling with DIC has not been applied to FRPCs in order to characterize the process induced residual stresses. As aforementioned, only in-plane stresses were measured for composites and the through-the-thickness residual stresses in thick UD FRPCs have not been considered in the literature. Therefore, there is ample room for conducting research on the quantification of through-the-thickness residual stresses in order to validate the process model predictions.

In this study, hole drilling with DIC was used to measure process induced transverse residual stresses in a pultruded thick composite $(20 \times 20 \mathrm{~mm})$ made of unidirectional glass/ polyester. Incremental hole drilling was employed with three different depths for five specimens in order to have a repeatable and reliable measured data. The influence of the DIC parameters (subset and step size) on the measured strain field after hole drilling was studied systematically. In order to evaluate the possible drilling induced stresses in the composite part, residual stress free specimens were prepared by heating them above the glass transition temperature $\left(T_{g}\right)$. Subsequently, the DIC with hole drilling procedure was applied on these stress free specimens to assess the isolated effects of drilling on the relaxed strain field and determine the drilling-affected-zone (DAZ). The drilling was simulated using a finite element based numerical model with predefined internal stress field. The released strain was obtained from the DIC and compared with the simulated strain field. The internal stress locked in the profile was back calculated by minimizing least square difference between experimental and numerical strain relaxation after hole drilling.

\section{Materials}

A pultruded rectangular bar having a cross section of $20 \times 20 \mathrm{~mm}$ and a length of 30 $\mathrm{mm}$ was investigated in this study. The part consists of unidirectional glass fiber with an industrial 'orthophthalic' unsaturated polyester resin which was characterized in [43]. 


\subsection{Average fiber volume fraction $\left(V_{f}\right)$}

The fiber volume fraction $\left(V_{f}\right)$ is a dominant factor in the final properties of a composite material. It is therefore necessary to obtain the average $V_{f}$ of the pultruded part for residual stress estimation in the numerical model. Optical microscopy was used to investigate the fiber/resin distribution over the complete cross-section of the part. Subsequently, an image processing algorithm based on circle finding was applied for fiber detection. The built-in circle finding algorithm available in MATLAB R2017a (function named 'imfindcircles') was used to estimate the number and geometry of fibers. As a work flow for the image process, fibers were detected with radius between 30-50 pixels, with dark object polarity, '0.97' as the sensitivity and '0.1' as the edge threshold in MATLAB. Any overlapped fibers were detected and the overlapped area was discarded in the total fiber area estimation. Nearly the complete cross section was scanned and a total of 142000 fibers were detected in $294 \mathrm{~mm}^{2}$ . The mean diameter of fibers was $35 \mu \mathrm{m}$ with $5 \mu \mathrm{m}$ standard deviation. The estimated average $V_{f}$ value for the profile was found to be 0.463 which gives a $66 \%$ fiber weight content (by assuming the fiber and resin density of $2560 \mathrm{~kg} / \mathrm{m}^{3}$ and $1120 \mathrm{~kg} / \mathrm{m}^{3}$, respectively $[44,45])$. The complete cross sectional view and one of the optical microscopy pictures of the cross section with the corresponding fiber detection are depicted in Fig. 2. Because of the tow based structure, randomly distributed resin layers are formed in the structure. The magnified region of the cross section in Fig. 2(b) was selected in purpose to show the resin rich layers between the tows.

Constituent mechanical properties of the glass fiber and the polyester are taken from the literature $[44,45]$. The effective mechanical properties of the FRPC were calculated with well established self consistent field micromechanics (SCFM) [44] method. Calculated effective properties for the UD profile $\left(V_{f}=0.463\right)$ is given in Table 3.

\subsection{Glass transition temperature $\left(T_{g}\right)$}

Stress-free specimens are necessary to investigate the effect of drilling on the strain field. Theoretically, the matrix stresses fully relax above $T_{g}[46,47]$. Additionally in [43], the 
elastic modulus of a pultrusion specific polyester resin system above its $T_{g}$ was presented around $100 \mathrm{MPa}$ which is almost 40 times lower than the room temperature elastic modulus. Due to the lower elastic modulus values around $T_{g}$, it can be concluded that the residual stresses are turned out to be negligible based on the corresponding process induced strains. Fiber/matrix stresses reappear during cooling down to room temperature, but the averaged composite stresses are assumed to remain zero provided that the temperature gradients can be assumed negligible in the specimen. A thermomechanical analyzer (TMA) from Mettler Toledo TMA/SDTA 840 was therefore employed to determine the glass transition temperature and to evaluate the thermal relaxation behaviour of the transverse residual stresses. Specimens taken from the center of the cross section were loaded with $0.01 \mathrm{~N}$ in the transverse direction to have a permanent contact of probe with the sample. The specimen was heated up to $160{ }^{\circ} \mathrm{C}$ with a heating rate of $3{ }^{\circ} \mathrm{C} / \mathrm{min}$, kept at $160{ }^{\circ} \mathrm{C}$ with $10 \mathrm{~min}$ and cooled down to $30^{\circ} \mathrm{C}$ with a cooling rate of $3{ }^{\circ} \mathrm{C} / \mathrm{min}$. This thermal cycle was repeated two times in order to identify the effect of thermal residual stress release in the first cycle and resulting residue for the second cycle. The TMA setup and the measured dimensional change, i.e. strain, in the transverse direction with applied temperature profile can be seen in Fig. 3. It is seen that there is a plateau in strain reading at around the glass transition temperature during the first heating ramp. This plateau can be explained with two competing mechanisms. One of these is the thermal expansion due to the temperature increase and the second one is the relaxation of the locked-in stresses, which cancel each other and resulting in a constant strain with temperature increase. This plateau is not seen during the second heating ramp, although there is a slight change in the strain rate at $130{ }^{\circ} \mathrm{C}$ which indicates the glass transition. Accordingly, the stress-free specimens for hole drilling with DIC were prepared by applying heating and cooling cycle shown in Fig. 3 in order to determine the DAZ using the DIC.

\section{Experimental Method}

A total of five specimens with three hole depths per specimen were considered in hole drilling with DIC experiments. The DIC setup was first calibrated and the noise level during 
the measurements was determined for six samples. The details of the DIC setup, calibration, noise levels and the post processing parameters used are explained in the following.

\subsection{DIC Setup, calibration and noise level}

The hole drilling with DIC approach is based on comparing two images taken before and after drilling with image process algorithms. The Aramis $4 \mathrm{M}$ system with $2048 \times 2048$ pixels camera with a lens of $50 \mathrm{~mm}$ focal length was used to measure the strain field obtained after drilling. The position and the orientation of the camera was calibrated with the ' $23 \times 18 \mathrm{~mm}$ ' calibration plate of Aramis. Once the system is calibrated, distance between the sample and the camera should remain the same for all of the samples. For this reason, all of the samples were cut out with the same dimensions (30 $\mathrm{mm}$ in the pulling direction) to ensure the distance between the camera and the sample kept constant. After the specimens were cut out from the profile, cross sections' surfaces were painted white firstly, then speckled with black spray paint.The surface was painted manually using a spray with a paint thickness of approximately $40 \mu \mathrm{m}$. According to [48] et al., the paint thickness does not have an influence on the results within elastic strain range $(\varepsilon<0.15 \%)$ which is comparable to our strain range.The speckle pattern was applied using a matt black aerosol spray paint. A homogenized speckle distribution was obtained by manually controlling the amount of paint exerted on the surface as also utilized in $[36,37]$. Putting the specimens at the same place after drilling was obtained by using a specific 'L-shaped' fixture.

The noise in the measured strains using the Aramis software was characterized based on two situations in which six different samples were analyzed:

i) taking two consecutive images without removing the specimen from the fixture.

ii) removing the specimen from the 'L-shaped' fixture and placing the same specimen back in place

The noise levels in the measured strains for the two situations mentioned above were estimated by calculating the strain difference between the reference and the second images obtained by the DIC. 


\subsection{Hole drilling with DIC}

The experimental procedure for the incremental hole drilling with DIC is schematically shown in Fig. 4. The specimens were cut from the same pultruded profile by a diamond saw with a nominal length of $30 \mathrm{~mm}$ and subsequently painted with a speckle pattern. The reference image before hole drilling was captured first. After taking the first image from the pristine specimen, the specimen was removed from the fixture and drilled in a vertical drill-press. A rubber air blower was utilized to clean the surface after each drilling step. Three different drill depths were consequtively used for the same specimen: $2 \mathrm{~mm}, 3 \mathrm{~mm}$ and $4 \mathrm{~mm}$. The nominal diameter of the drill was $3 \mathrm{~mm}$ and the drilling speed was chosen at $300 \mathrm{rpm}$ as used in [36] which gave negligible thermal effects to the DAZ. Afterwards, the drilled specimen was placed in the fixture again. This procedure was repeated for each of the drilling increments. The relaxed strain distribution around the hole was measured by the DIC. Three independent strain fields were measured for three drilling depths during the incremental drilling for each specimen. A total of 15 hole drilling with DIC experiments were carried out, i.e. five specimens cut from the pultruded profile and three incremental drilling per specimen.

\subsection{Post-process and DIC Parameters}

The speckled cross-section and the corresponding ROI used in the DIC are shown in Fig. 5. Apart from the full field strain distribution in Cartesian coordinate system, i.e. $\varepsilon_{X}$ in the $X$-direction and $\varepsilon_{Y}$ in the $Y$-direction, the strain relaxation around the drilled hole was considered by incorporating the radial and tangential strain components with respect to the hole center along the lines indicated in Fig. 5a. Ideally, the radial or tangential strains along the lines right, left, top and bottom in Fig. 5a should be identical. However, this is not the case in the pultruded profile due to the locally non-uniform fiber distribution as shown in Fig. 2 [49] and a possible noise in the measured strain. Therefore, the average of the strain values along right, left, top and bottom lines from the hole boundary to the outer edge is used in the present work for radial and tangential strains. Accordingly, the radial and tangential strain distribution $\left(\varepsilon_{r}\right.$ and $\varepsilon_{t}$, respectively) in the radial direction were 
calculated based on the measured $\varepsilon_{X}$ and $\varepsilon_{Y}$ along right, left, top and bottom lines shown in Fig. 5a:

$$
\begin{aligned}
\varepsilon_{r} & =\frac{\varepsilon_{X}^{\text {right }}+\varepsilon_{X}^{l e f t}+\varepsilon_{Y}^{t o p}+\varepsilon_{Y}^{\text {bottom }}}{4} \\
\varepsilon_{t} & =\frac{\varepsilon_{Y}^{\text {right }}+\varepsilon_{Y}^{\text {left }}+\varepsilon_{X}^{\text {top }}+\varepsilon_{X}^{\text {bottom }}}{4}
\end{aligned}
$$

The relaxed strain field captured after hole drilling was handled with image correlation between reference image without hole and the second image with hole. Therefore, the results are expected to be directly dependent on the DIC parameters used in the image correlation. As pointed out in the literature, sensitivity of the DIC is highly linked to subset size, step size and ROI size [41]. To understand the influence of DIC parameters on the results, three different step sizes (15, 20 and 25 pixels) and four different subset sizes $(20,25,30$ and 35 pixels) were analyzed and presented with constant region of interest of $800 \times 800$ pixels shown in Fig. 5(b). The pixel scale was 44 pixels $/ \mathrm{mm}$.

\section{Numerical Model}

A numerical model was developed using the commercial finite element software package ABAQUS. This model was used to interpret the released strain distribution measured after hole drilling and estimate the initial stress state locked in the profile after the manufacturing process and before hole drilling. A three-dimensional (3D) quasi-static analysis was carried out to simulate the hole drilling process and predict the corresponding strain release.

A 20-node quadratic brick elements (C3D20R) were used to model the pultruded specimens with a dimension of $20 \times 20 \times 30 \mathrm{~mm}$ employed in the hole drilling. A total of 20592 elements were used. In order to reduce the computational time, a quarter model was considered due to symmetry boundary conditions. The material properties were assumed to be transversely isotropic as presented in Table 3. The residual stress distribution locked in 
the profile was introduced to the 3D model as an initial predefined stress state by using the SIGINI subroutine in ABAQUS. Two different initial stress states were considered:

- Uniform stress: A uniform tensile stress distribution was defined as a relatively simple approach by constraining the outer edges. The aim is to estimate the magnitude of the initial stress which gives the similar measured strain after hole drilling.

- Non-uniform stress: The non-uniform stress distribution found in [7] was used as a predefined stress state which is obviously more complex than the uniform stress state.

The boundary conditions together with the initial stress states defined using the uniform and non-uniform stress distributions are illustrated in Fig.6.

The hole drilling was simulated by deleting the elements at the hole area indicated in Fig. 6(a). The element deletion was handled by assigning considerably small elastic properties to the drilled region. The elastic properties of the material at the drilled area were multiplied by $10^{-6}$ as in [18]. To illustrate, the predicted released strain distributions in Y-direction after hole drilling with a $4 \mathrm{~mm}$ depth are shown in Fig. 6(a) for the initially uniform stress state (6.25 MPa) and in Fig.6(b) for the initially non-uniform stress state (average 6.25 MPa at the center region with $3 \mathrm{~mm}$ diameter). It is seen that the released strain distribution is found to be very close for the uniform and non-uniform predefined stress states.

In order to find the magnitude of the initial stress field which gives the same released strain distribution after hole drilling, a parametric study was performed based on the magnitude of the initial stress state varying from 4.25 to $9.75 \mathrm{MPa}$ with a $0.125 \mathrm{MPa}$ increment. In the parameter analysis, the average tensile stress at the hole boundary was considered for the non-uniform stress state. The minimum least square difference between the experimental and the numerical strain decay was found as Eq. 3.

$$
S=\sum_{r}\left(\varepsilon_{D I C}(r)-\varepsilon_{A B A Q U S}(r)\right)^{2}
$$

Where $r$ was the position between the hole boundary and the outer edge. The stress value which gave minimum $S$ was considered as the corresponding initial stress value. 


\section{Results and Discussions}

\subsection{Noise level}

The mean values and standard deviations of the noise levels obtained for the 6 specimens as explained in Section 3 are listed in Table 4 and Table 5 based on different DIC parameter sets, i.e. subset size and step size. As it is seen in Table 4, the maximum values of the mean and standard deviation of the measured strain difference for the case without moving the specimens were found to be $-7.9[\mu \mathrm{m} / \mathrm{m}]$ and $41.2[\mu \mathrm{m} / \mathrm{m}]$, respectively. On the other hand, the maximum mean and standard deviation of the noise were estimated as $-6.8[\mu \mathrm{m} / \mathrm{m}]$ and $42.7[\mu \mathrm{m} / \mathrm{m}]$, respectively, as seen in Table 5 for the case where the specimens were moved and placed back to the fixture. The first values in Table 4 and Table 5 are the mean noise which is the average of strain values through the cross section. The second values, that are in parentheses, are standard deviation of strain values through the cross section. The comparison of noise values between Table 5 and 6 shows that there is no significant effect of relocating the sample to its reference place after drilling the hole. As a general trend, bigger subset and step size result in lower deviation in the noisy field. On the other hand, bigger subset and step sizes lead lower resolution for correlation. Additionally, higher step size magnify the size of the drilling affected zone (DAZ). As an optimum parameter set, $30 \times 30$ pixels of subset and 15 pixels step size was selected.

\subsection{Stress Free Specimens and DAZ}

In order to evaluate the influence of the drilling on the released strain distribution and investigate the DAZ, the released strain distribution after hole drilling was measured for the stress free specimens which were prepared by applying the heating cycle as seen in Fig. 3. The speckle damage, possible drilling induced plastic deformation and the local increase in temperature may be the reasons for having a higher strain around the hole. A total of six specimens was investigated for the incremental hole drilling. The relased strain decays after hole drilling measured on the cross sections of these stress free specimens can be seen in Fig. 7 for different DIC parameters. Fig. 7 shows the average $\varepsilon_{r}$ and $\varepsilon_{t}$ (see Eq. 1 and Eq. 2) of 6 
specimens for the hole depth of $4 \mathrm{~mm}$. There is no consistent trend for different DIC parameter sets. As it is seen in Fig. 7, the strain distribution around the hole shows that drilling was effective on a local area around the hole, i.e. DAZ. The strain decays are suddenly getting closer to the zero without showing a slow transition after a specific distance from the hole boundary. This behaviour can be concluded as a strong sign to be a consequence of drilling. With a linear elastic behaviour assumption the strain decays are supposed to have a smooth gradient form the hole boundary to the outer edges. After approximately 2 $\mathrm{mm}$ from the hole boundary, the effect of drilling dissappeared and the strain varied slightly between -60 and $+60 \mu \mathrm{m} / \mathrm{m}$ which was expected due to noise as assessed before. The size of DAZ (2 mm from the hole boundary) is approximatey 1.3 times the hole radius of $1.5 \mathrm{~mm}$, which is similar to the value found in [50] in which the DAZ was determined as 1.7 times the hole radius. The subset size of 30 and step size of 15 were selected as mentioned before. Still, results of all DIC parameter sets applied were shown in Fig. 7 to indicate the effect of parameters. Although the general trend of released strain decay after DAZ was found to be similar for different DIC parameters, the step sizes of 20 and 25 resulted in larger DAZ. The influence of hole depth on the released strain distribution is depicted in Fig. 8 with three incremental steps. There was no significant effect of hole depth on the released strain distribution except in the DAZ. The slight change in $\varepsilon_{r}$ and $\varepsilon_{t}$ after $2 \mathrm{~mm}$ can also be seen in the zoomed plot in Fig. 8.

\subsection{Specimens with Residual Stress}

Fig. 9 shows strain decay of $\varepsilon_{r}$ and $\varepsilon_{t}$ from the hole boundary to the edge of the cross section along the main lines for different DIC parameter sets. A total of five different specimens was inspected as mentioned before and the results in Fig. 9 are shown for the average of the five specimens. It can be observed that the step size differentiated the results within the DAZ especially for $\varepsilon_{r}$. A higher step size reduced the scatter in strain within the DAZ. Although the subset size was reported to smoothen the strain distributions [41], here the subset size is not as dominant as step size on the results. The average strain distributions 
along right, left, top and bottom (see Fig. 5) for the specimens are shown in Fig. 10 for a subset size of 30 and a step size of 15 . A similar trend was found for the strain distributions in radial and tangential directions along the lines right, left, top and bottom. The slight variation in strain distribution outside the DAZ was mainly due to non-uniform fiber volume content and the existing noise in the measurements. The maximum measured released strain at approximately $2 \mathrm{~mm}$ from hole edge was found to be in the range of 200-400 $\mu \mathrm{m} / \mathrm{m}$.

The initial stress was estimated based on the radial and tangential strain components for each hole depth using the numerical model with uniform and non-uniform stress distributions (see Fig. 6). The estimated initial stress state range using these two modelling frameworks was found to be close to each other, i.e. approximately 5.125-7.500 MPa for the non-uniform stress distribution (Fig. 6a) and 5.375-6.375 MPa for the uniform stress distribution (Fig. 6b) with different drilled hole depths. Note that the non-uniform stress field used in the analysis was obtained with a process model which was developed for the same material system in [7] as aforementioned. However, the process parameters for the corresponding profile in the current work was not known and might not be same as the parameters defined in the comprehensive process model taken from [7]. In addition, the non-uniformities in the fiber structure or the variations in the process conditions would cause stress non-uniformity in different scales which is not possible to observe with a macro scale stress measurement technique presented in this study. As a result of this and due to a similar initial stress state obtained from the uniform and non-uniform stress distribution models, only uniform initial stress state was considered for the remaining part of this study, i.e. comparing the estimations with the DIC measurements. Fig. 11(a,b,c) shows the average strain decay $\left(\varepsilon_{r}\right.$ and $\varepsilon_{t}$ ) for five specimens with standard deviation and the corresponding predicted strain distribution based on the estimated initial stress state for each hole depths, i.e. 2,3 and 4 $\mathrm{mm}$. There was also a slight influence of the hole depth as the magnitude of both tangential and radial strain increased with the hole depth as seen in Fig. 11(d). The initial stress values from the radial and tangential components of the average strain were estimated as 5.375 MPa and 6.250 Mpa for the $2 \mathrm{~mm}$ hole depth, 5.500 MPa and 6.375 MPa for the 3 
$\mathrm{mm}$ hole depth and 6.250 $\mathrm{MPa}$ and 6.250 $\mathrm{MPa}$ for the $4 \mathrm{~mm}$ hole depth, respectively using the uniform stress distribution model shown in Fig. 6a.

The individual stress estimations for each specimen and hole depth are listed in Table 6 based on handling the measured strain in radial and tangential directions using the uniform stress state in the numerical model. The standard deviation of the five tested specimens was found to be between 10.6-28.9 \% of the average values. This indicates a good reproducibility of the determined residual stress state as compared with the results presented in [36] in which a standard deviation of $10 \%$ was found for a neat epoxy specimen considering the variations induced by the fiber distributions in the current case. Moreover, the outof-plane deformations after hole drilling were not taken into accout in the present study, which probably further increases the deviation between the simulation and the experiment. The average of all estimated stress values in Table 6 is $6.1 \mathrm{MPa}$. This value agrees well with the stress levels predicted in [7], providing good supporting evidence for the validity of the presented modelling approach for the pultrusion process. Further, this is $15 \%$ of the transverse strength value reported in literature for a comparable pultruded material [13] and thus can be considered relevant for the effective structural performance of such a profile.

The full field strain distribution obtained by DIC and 3D numerical model with an initial uniform stress state of 6.1 MPa are shown in Fig. 12 for different hole depth values. A good agreement was obtained for the measured and predicted strain distribution though the measured strain field scatters due to the non-uniform fiber distribution, possible fiber misalignment in the pulling direction and inherent noise in the measurement.

\section{Conclusions}

In the presented work, the hole drilling method with DIC was used to measure the released strain distribution due to process induced residual stresses locked in a pultruded unidirectional glass/polyester profile $(20 \times 20 \times 30 \mathrm{~mm})$. A total of 5 specimens was analysed 
and three different hole depths of 2,3 and $4 \mathrm{~mm}$ were employed per specimen in the incremental hole drilling experiments in order to obtain repeatable and reliable measured data. The noise level in the measurements was determined as $60 \mu \mathrm{m} / \mathrm{m}$ which was found to be relatively small as compared with the measured released strain after hole drilling. The DAZ was determined by drilling a hole with $3 \mathrm{~mm}$ diameter in stress free specimens which were prepared by heating them above $T_{g}$. It was found that drilling affected a region of approximately $2 \mathrm{~mm}$ around the hole edge. Therefore, the strain distribution beyond $2 \mathrm{~mm}$ from hole edge was considered in the initial residual stress estimation. The influence of different DIC parameters was found to be negligible outside the DAZ.

A numerical model was developed using the finite element method to estimate the initial residual stress which gave the same strain distribution as compared with the measured strain field after hole drilling. A uniform and non-uniform initial stress state were defined as a predefined stress in the model. The aim was to compare the effect of a simple and a more complex stress state on the estimated stress. A maximum of $20 \%$ difference was found in the estimated stresses for different initial stress states. To propose a self standing method, stress estimation with uniform stress field was presented which does not require an extensive process model. The calculated residual stress was $5.8 \mathrm{MPa}$ and $6.4 \mathrm{MPa}$ using the measured radial and tangential strain data, respectively. The difference could be due to the non-uniform local fiber volume content and possible out-of-plane deformations. The results differ between the five specimens and the three drilling depths. Considering the variability of the fibre distribution and results reported earlier for hole drilling measurements on neat resin [36], the coefficient of variation for all measurements reported here $(=17.5 \%)$ is believed to be reasonable and acceptable. Good agreement was obtained with the process model presented in [7]. As a future study, the different speckling techniques with different hole diameters and drilling speeds can be researched to find the optimum measurement conditions with respect to the estimated stresses. 


\section{Acknowledgements}

This work is part of the project named Modelling the multi-physics in resin injection pultrusion (RIP) of complex industrial profiles which has been granted by the Danish Council for Independent Research - Technology and Production Sciences (DFF/FTP), Grant no. DFF- 6111-00112. 


\section{References}

[1] I. Baran. Pultrusion : state-of-the-art process models. Shrewsbury: Smithers Rapra, 2015.

[2] T. Starr. Pultrusion for Engineers. Taylor \& Francis, 2000.

[3] A. Babeau, S. Comas-Cardona, C. Binetruy, and G. Orange. Modeling of heat transfer and unsaturated flow in woven fiber reinforcements during direct injection-pultrusion process of thermoplastic composites. Composites Part A: Applied Science and Manufacturing, 77:310 - 318, 2015.

[4] I. Tena, M. Sarrionandia, J. Torre, and J. Aurrekoetxea. The effect of process parameters on ultraviolet cured out of die bent pultrusion process. Composites Part B: Engineering, 89:9 - 17, 2016.

[5] I. Baran, K. Cinar, N. Ersoy, R. Akkerman, and J.H. Hattel. A Review on the Mechanical Modeling of Composite Manufacturing Processes. Archives of Computational Methods in Engineering, 24(2):365$395,2017$.

[6] M.R. Wisnom, M. Gigliotti, N. Ersoy, M. Campbell, and K.D. Potter. Mechanisms generating residual stresses and distortion during manufacture of polymer-matrix composite structures. Composites Part A: Applied Science and Manufacturing, 37(4):522-529, 2006.

[7] I. Baran, C.C. Tutum, M.W. Nielsen, and J.H. Hattel. Process induced residual stresses and distortions in pultrusion. Composites Part B: Engineering, 51:148-161, 2013.

[8] I. Baran, C. C. Tutum, and J. H. Hattel. Probabilistic thermo-chemical analysis of a pultruded composite rod. Venice, Italy, June 2012. In: Proceedings of the 15th European conference on composite materials, ECCM-15.

[9] I. Baran, J.H. Hattel, and R. Akkerman. Investigation of process induced warpage for pultrusion of a rectangular hollow profile. Composites Part B: Engineering, 68:365 - 374, 2015.

[10] I. Baran, R. Akkerman, and J.H. Hattel. Modelling the pultrusion process of an industrial L-shaped composite profile. Composite Structures, 118:37-48, 2014.

[11] I. Baran, C.C. Tutum, and J. H. Hattel. The internal stress evaluation of pultruded blades for a darrieus wind turbine. Key engineering materials, 554-557:2127-2137, 2013. Main theme: The Current State-of-the-Art on Material Forming.

[12] I. Baran. Analysis of pultrusion process for thick glass / polyester composites : transverse shear stress formations. Advanced Manufacturing: Polymer \& Composites Science, 0340:1-22, 2017.

[13] A. Quadrino, R. Penna, L. Feo, and N. Nisticò. Mechanical characterization of pultruded elements: Fiber orientation influence vs web-flange junction local problem. Experimental and numerical tests. Composites Part B: Engineering, 142(November 2017):68-84, 2018.

[14] K. Cinar, U.E. Ozturk, N. Ersoy, and M.R. Wisnom. Modelling manufacturing deformations in corner sections made of composite materials. Journal of Composite Materials, 48(7):799-813, 2014.

[15] Z. Yuan, Y. Wang, X. Peng, J. Wang, and S. Wei. An analytical model on through-thickness stresses 
and warpage of composite laminates due to toolpart interaction. Composites Part B: Engineering, 91:408 - 413, 2016.

[16] N. Ersoy and O. Vardar. Measurement of Residual Stresses in Layered Composites by Compliance Method. Journal of Composite Materials, 34:575-598, 2000.

[17] G.S. Schajer and L. Yang. Residual-stress measurement in orthotropic materials using the hole-drilling method. Experimental Mechanics, 34(4):324-333, 1994.

[18] M.M. Shokrieh and A.R. Ghasemi K. Simulation of Central Hole Drilling Process for Measurement of Residual Stresses in Isotropic, Orthotropic, and Laminated Composite Plates. Journal of Composite Materials, 41(4):435-452, 2007.

[19] C. Garza, R.Das, A. Shterenlikht, and M. Pavier. Measurement of assembly stress in composite structures using the deep-hole drilling technique. Composite Structures, 202:119 - 126, 2018.

[20] M.G. Bateman, O.H. Miller, T.J. Palmer, C.E.P. Breen, E.J. Kingston, D.J. Smith, and M.J. Pavier. Measurement of residual stress in thick section composite laminates using the deep-hole method. International Journal of Mechanical Sciences, 47(11):1718 - 1739, 2005.

[21] M.B. Prime. Cross-Sectional Mapping of Residual Stresses by Measuring the Surface Contour After a Cut. Journal of Engineering Materials and Technology, 123(2):162, 2001.

[22] R.Y. Kim and H.T. Hahn. Effect of curing stresses on the first ply-failure in composite laminates. Journal of Composite Materials, 13(1):2-16, 1979.

[23] J. W. Kim and D. G. Lee. Measurement of residual stresses in thick composite cylinders by the radial-cut-cylinder-bending method. Composite Structures, 77:444-456, 2007.

[24] R.G. Reid and R. Paskaramoorthy. A novel method to measure residual stresses in unidirectional GFRP. Composite Structures, 88(3):388-393, 2009.

[25] ASTM E837 13a. Standard Test Method for Determining Residual Stresses by the Hole-Drilling StrainGage Method. 2013.

[26] Soete W. Measurement and Relaxation of Residual Stress. Sheet Met Ind, 26:1269-81, 1949.

[27] O. Sicot, X.L. Gong, A. Cherouat, and J. Lu. Determination of Residual Stress in Composite Laminates Using the Incremental Hole-drilling Method. Journal of Composite Materials, 37(9):831-844, 2003.

[28] P. Pagliaro and B. Zuccarello. Residual stress analysis of orthotropic materials by the through-hole drilling method. Experimental Mechanics, 47(2):217-236, 2007.

[29] M.M. Shokrieh and A. R. Ghasemi K. Determination of Calibration Factors of the Hole Drilling Method for Orthotropic Composites using an Exact Solution. Journal of Composite Materials, 41(19):22932311, 2007.

[30] S. Akbari, F. Taheri-Behrooz, and M.M. Shokrieh. Characterization of residual stresses in a thinwalled filament wound carbon/epoxy ring using incremental hole drilling method. Composites Science 
and Technology, 94:8-15, 2014.

[31] Z. Wu and J. Lu. Study of Surface Residual Stress by Three-Dimensional Displacement Data at a Single Point in Hole Drilling Method . ASME. J. Eng. Mater. Technol., 122(19):215-220, 1999.

[32] D.V. Nelson. Residual stress determination by Hole drilling combined with optical methods. Experimental Mechanics, 50(2):145-158, 2010.

[33] M. Mehdikhani, M. Aravand, B. Sabuncuoglu, M.G. Callens, S.V. Lomov, and L. Gorbatikh. Full-field strain measurements at the micro-scale in fiber-reinforced composites using digital image correlation. Composite Structures, 140:192-201, 2016.

[34] Tiren He, Liu Liu, and Andrew Makeev. Uncertainty analysis in composite material properties characterization using digital image correlation and finite element model updating. Composite Structures, 184:337 - 351, 2018.

[35] J. Lienhard and L. Schulenberg. Strain rate dependent multiaxial characterization of long fiber reinforced plastic. Composites Part B: Engineering, 141:164 - 173, 2018.

[36] J. Jakobsen, J. Andreasen, and M. Jensen. A novel biaxial specimen for inducing residual stresses in thermoset polymers and fibre composite material. Journal of Composite Materials, 49(22):2723-2731, 2014.

[37] J.D. Lord, D. Penn, and P. Whitehead. The Application of Digital Image Correlation for Measuring Residual Stress by Incremental Hole Drilling. Applied Mechanics and Materials, 13-14:65-73, 2008.

[38] J. S. Harrington and G. S. Schajer. Measurement of Structural Stresses by Hole-Drilling and DIC. Experimental Mechanics, 57(4):559-567, 2017.

[39] Y. Ma, X. Yao, and D. Zhang. Axially symmetrical stresses measurement in the cylindrical tube using DIC with hole-drilling. Optics and Lasers in Engineering, 66:174-180, 2015.

[40] A. Baldi. Residual Stress Measurement Using Hole Drilling and Integrated Digital Image Correlation Techniques. Experimental Mechanics, 54(3):379-391, 2014.

[41] M. Kashfuddoja, R.G.R. Prasath, and M. Ramji. Study on experimental characterization of carbon fi ber reinforced polymer panel using digital image correlation : A sensitivity analysis. Optics and Lasers in Engineering, 62:17-30, 2014.

[42] D. V. Nelson, A. Makino, and T. Schmidt. Residual stress determination using hole drilling and 3D image correlation. Experimental Mechanics, 46(1):31-38, 2006.

[43] I. Baran, R. Akkerman, and J.H. Hattel. Material characterization of a polyester resin system for the pultrusion process. Composites Part B: Engineering, 64:194 - 201, 2014.

[44] T.A. Bogetti and Jr J.W. Gillespie. Process-induced stress and deformation in thick-section thermoset composite laminates. Journal of Composite Materials, 26(5):626-660, 1992.

[45] Atlac 382 Technical Data Sheet, DSM Composite Resins (2003). 
[46] J.M. Svanberg and J.A. Holmberg. Prediction of shape distortions part i. fe-implementation of a path dependent constitutive model. Composites Part A: Applied Science and Manufacturing, 35(6):711 $721,2004$.

[47] S. Nelson, A. Hanson, T. Briggs, and B. Werner. Verification and validation of residual stresses in composite structures. Composite Structures, 194:662 - 673, 2018.

[48] J. A. Pérez, S. Coppieters, and D. Debruyne. Influence of the paint coating thickness in digital image correlation experiments. International Journal of Computer, Electrical, Automation, Control and Information Engineering, 9(7):1660 - 1664, 2015.

[49] I. Baran. Analysis of the local fiber volume fraction variation in pultrusion process. AIP Conference Proceedings, 1896(1):030029, 2017.

[50] G. S. Schajer, B. Winiarski, and P. J. Withers. Hole-Drilling Residual Stress Measurement with Artifact Correction Using Full-Field DIC. Experimental Mechanics, 53(2):255-265, 2013.

[51] J. Blaber, B. Adair, and A. Antoniou. Ncorr: Open-Source 2D Digital Image Correlation Matlab Software. Experimental Mechanics, 55(6):1105-1122, 2015.

[52] K. Cinar, U.E. Ozturk, N. Ersoy, and M.R. Wisnom. Modelling manufacturing deformations in corner sections made of composite materials. Journal of Composite Materials, 48(7):799-813, 2013.

[53] I. Baran, J.H. Hattel, R. Akkerman, and C.C. Tutum. Mechanical Modelling of Pultrusion Process: 2D and 3D Numerical Approaches. Applied Composite Materials, 22(1):99-118, 2014.

[54] C.C. Tutum, I. Baran, and J.H. Hattel. Utilizing multiple objectives for the optimization of the pultrusion process based on a thermo-chemical simulation. 554:2165-2174, 2013.

[55] C.C. Tutum, K. Deb, and I. Baran. Constrained efficient global optimization for pultrusion process. Materials and Manufacturing Processes, 30(4):538-551, 2015. 


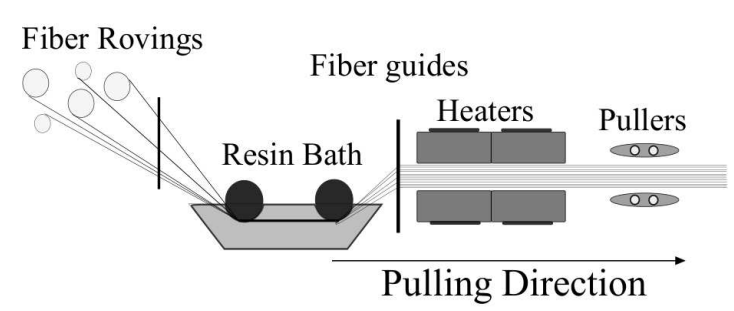

(a)

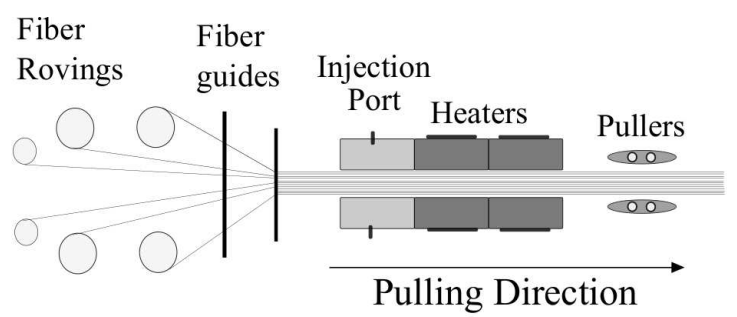

(b)

Figure 1: Schematic view of the resin bath pultrusion(a) and the resin injection pultrusion(b).

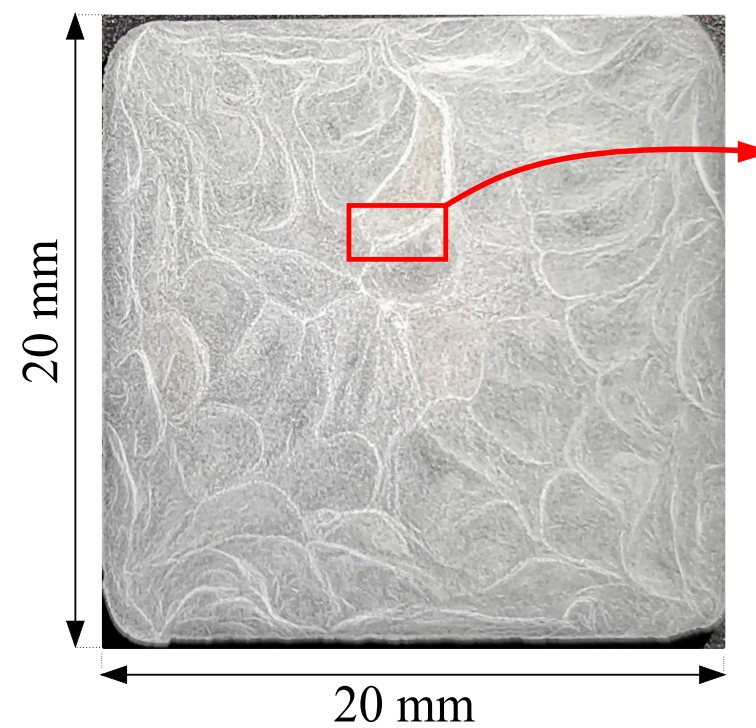

(a)

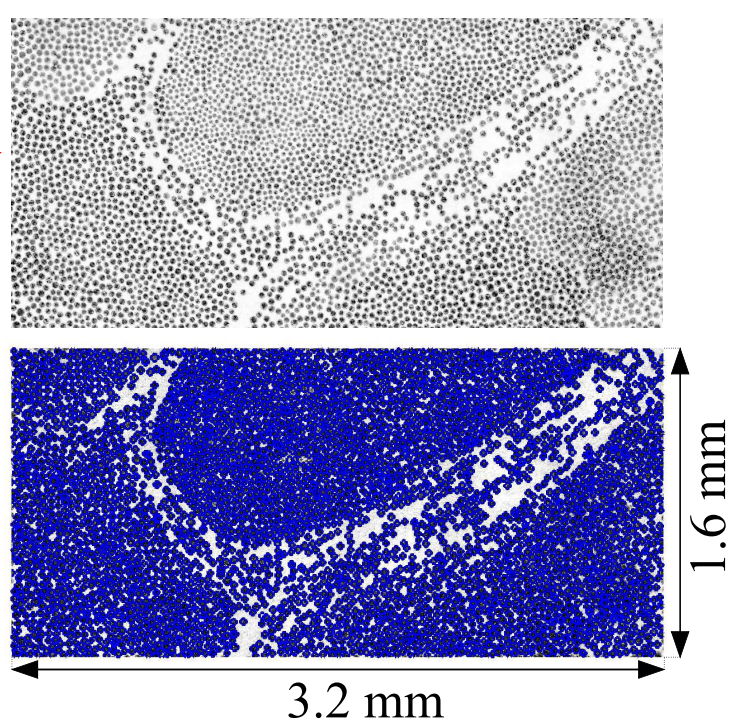

(b)

Figure 2: Cross sectional view of the pultruded profile(a) and the detected fibers for a region of $3.2 \times 1.6 \mathrm{~mm}$ (b). 

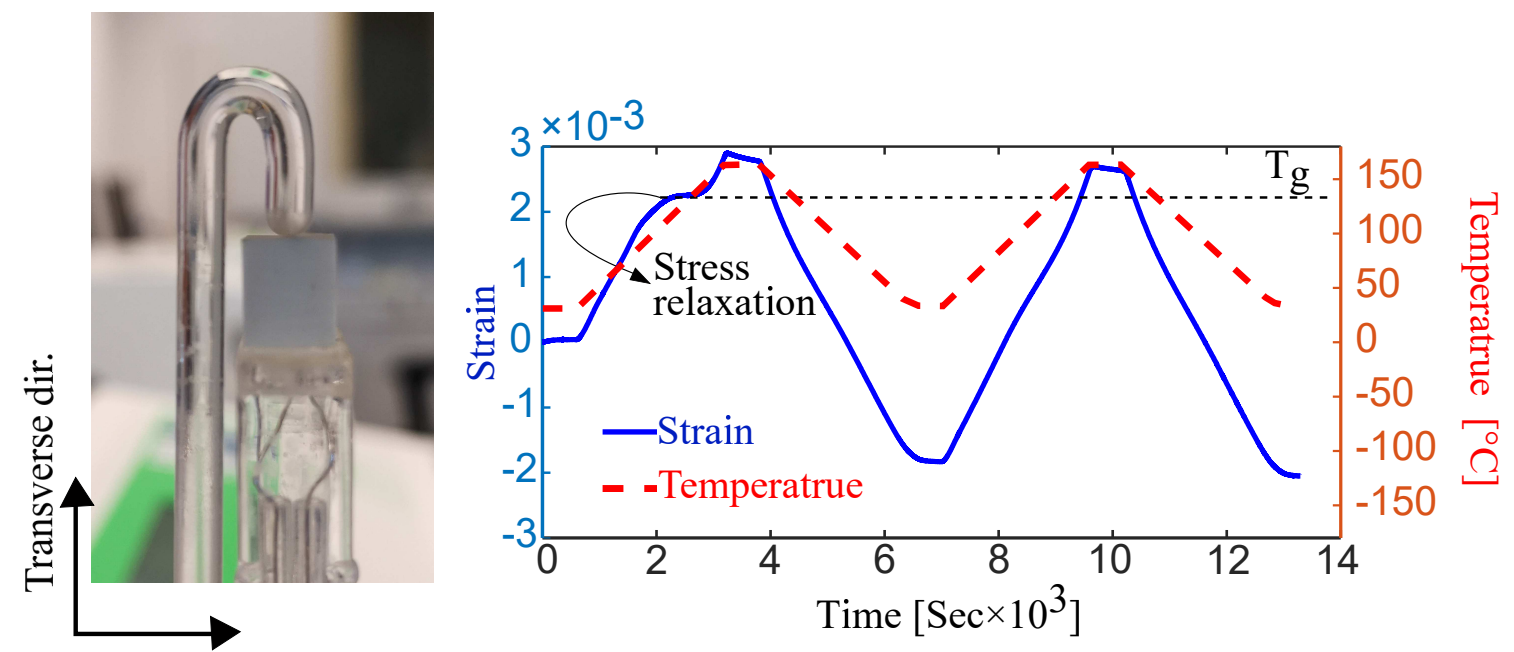

Fiber dir.

Figure 3: TMA setup and the specimen where the test was performed in the transverse direction (a). The obtained TMA curve of the tested specimens(b). The relaxation of residual stresses are clearly seen in the first heating ramp and the $T_{g}=130^{\circ} \mathrm{C}$ is obtained by the change in thermal expansion (dimensional change).

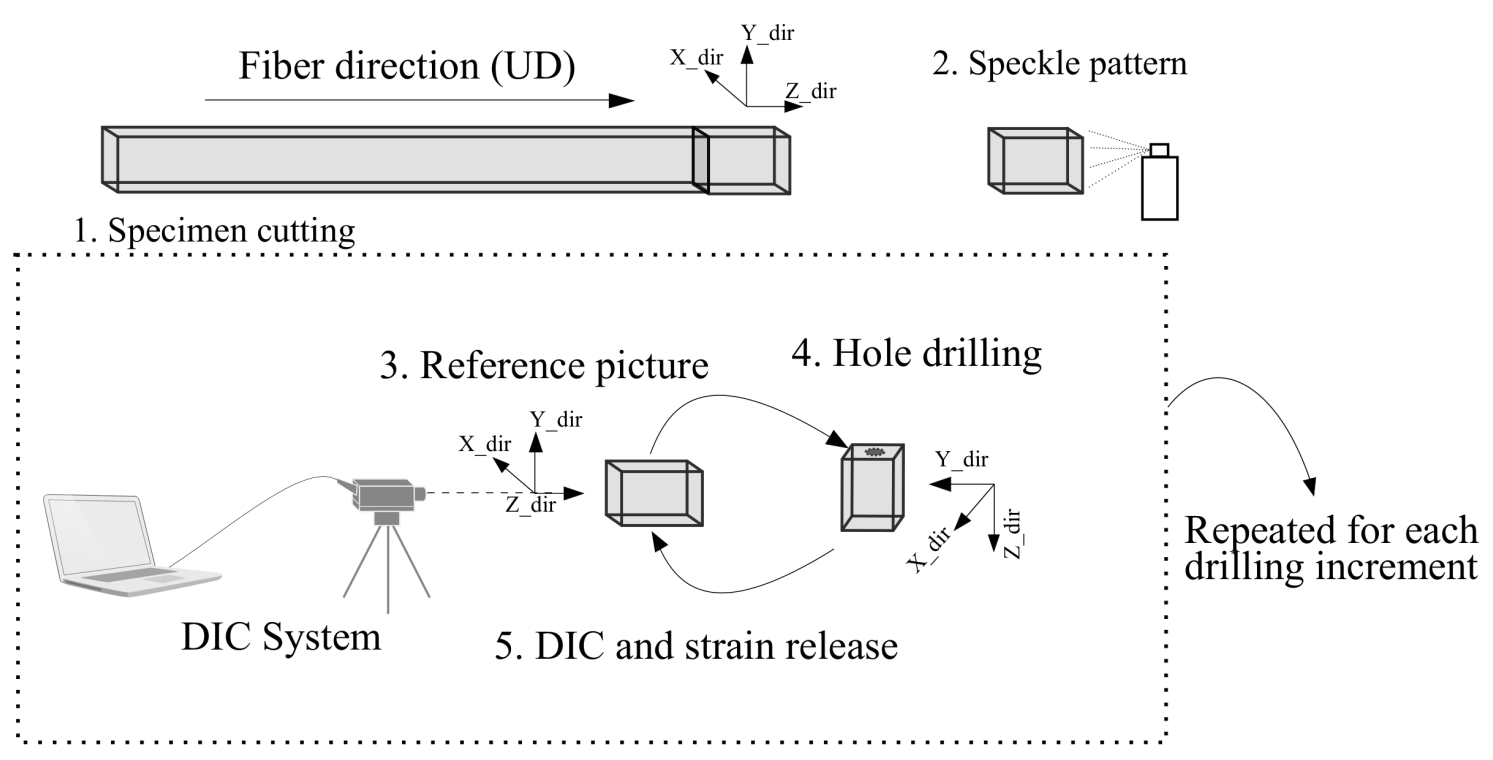

Figure 4: Schematic view of the hole drilling process and the corresponding steps: 1) Specimens were cut out from a long pultruded profile, 2) Cross sections were painted with spray paint, 3) Photos of the undrilled specimens were taken as a reference image, 4) Specimens were drilled under a press drill and 5) Photos of the drilled specimens were taken and strain release was calculated by the DIC algorithm. 


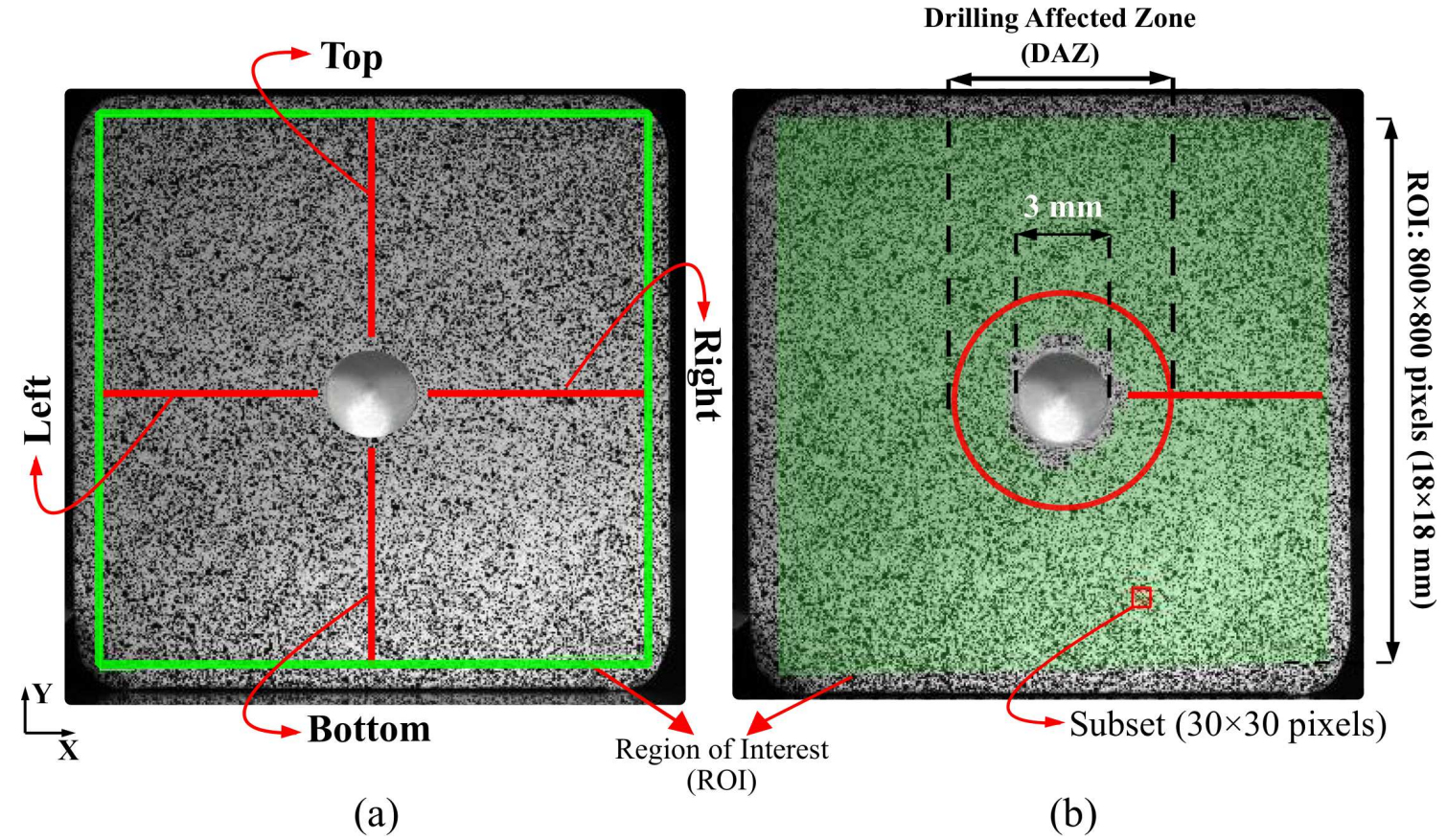

(a)

(b)

Figure 5: Speckled surface with four main lines (right, left, top and bottom) on which the radial and tangential strains are averaged (a). The ROI, subset used in DIC and the illustration of the DAZ (b). 


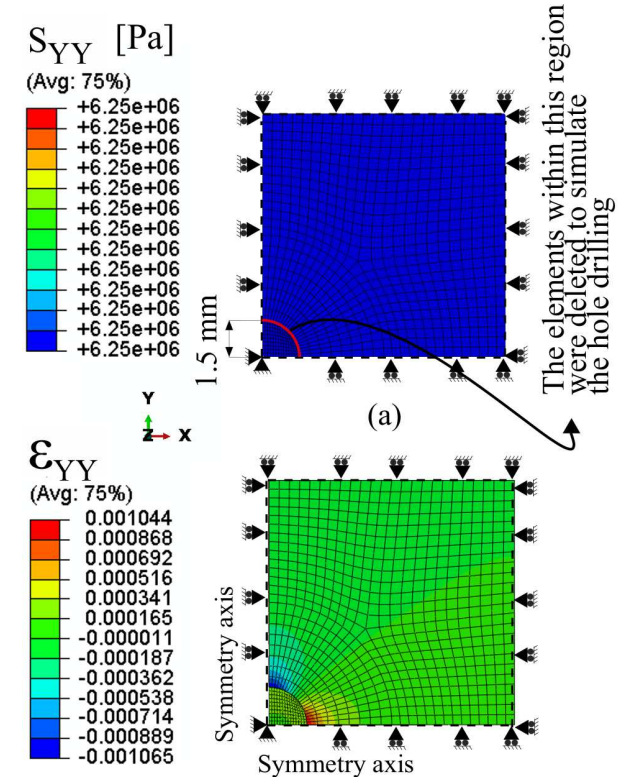

(c)

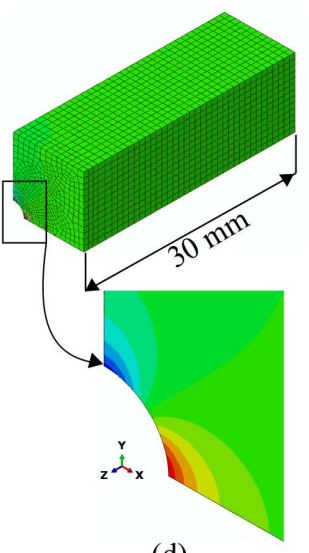

(d)
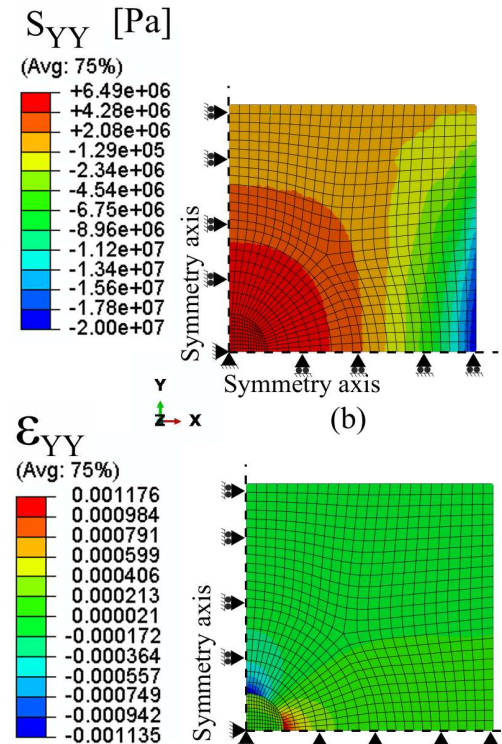

$-0.001135$

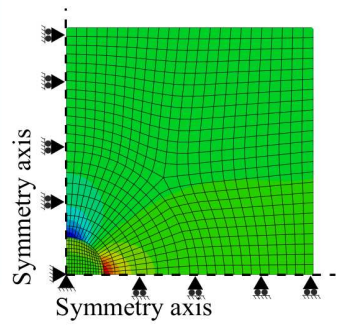

(e)

Figure 6: The model geometry and boundary conditions for uniform stress state(a). The initial non-uniform stress state with average 6.25 $\mathrm{MPa}$ at the hole boundary (b). The relaxed strain distribution at the cross section of the 3D domain after drilling simulation with $4 \mathrm{~mm}$ depth of drill for $6.25 \mathrm{MPa}$ uniform residual stress (c). The relaxed strain distribution with isometric view (d). The relaxed strain distribution at the cross section of the 3D domain after drilling simulation with $4 \mathrm{~mm}$ depth of drill for $6.25 \mathrm{MPa}$ non-uniform residual stress $(\mathrm{e})$

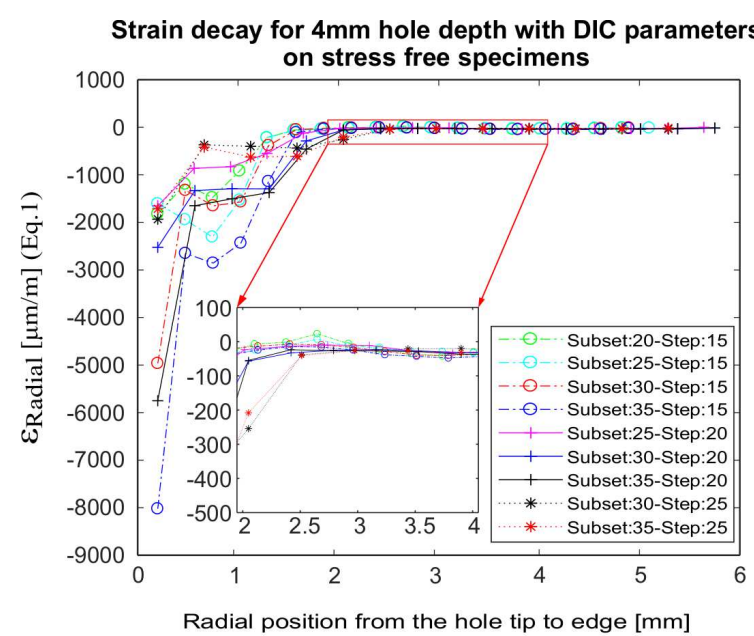

(a)

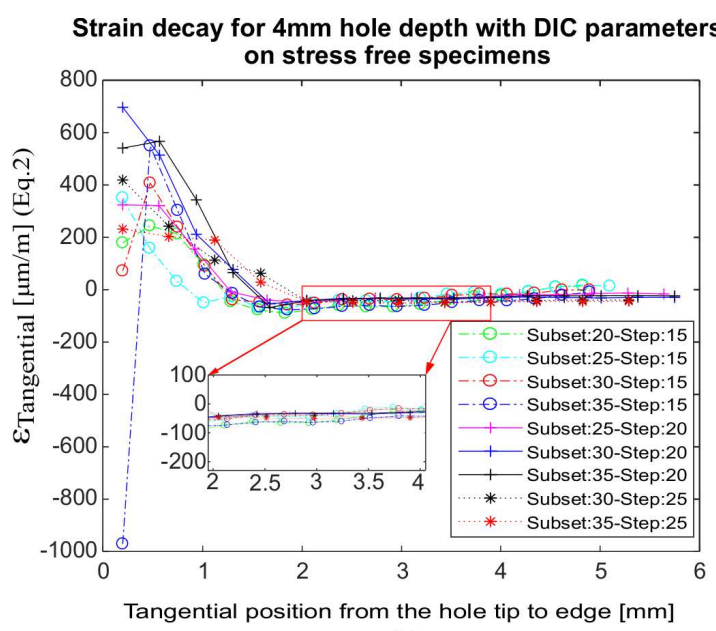

(b)

Figure 7: Strain decay of stress free specimens for different DIC parameters; $\varepsilon_{r}(\mathrm{a})$ and $\varepsilon_{t}(\mathrm{~b})$. 


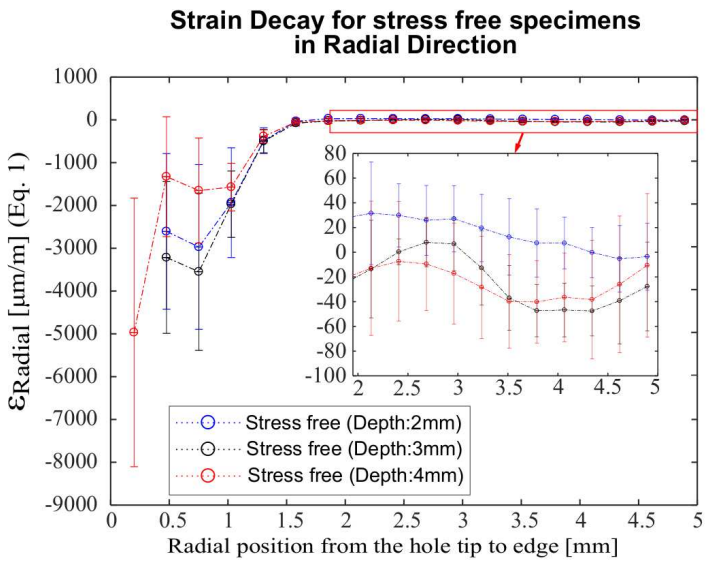

(a)

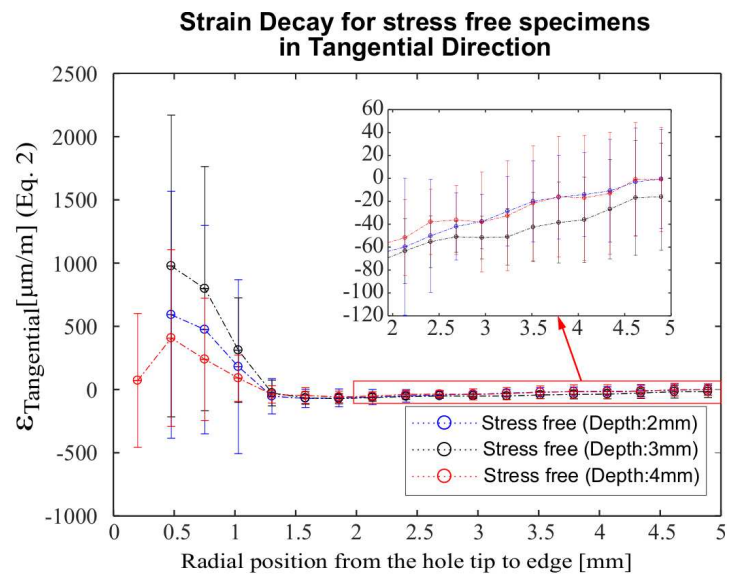

(b)

Figure 8: Strain decay of stress free specimens for different hole depths; $\varepsilon_{r}$ (a) and $\varepsilon_{t}$ (b) (subset size:30, step size:15).

Strain Decay for $4 \mathrm{~mm}$ hole depth with DIC parameters

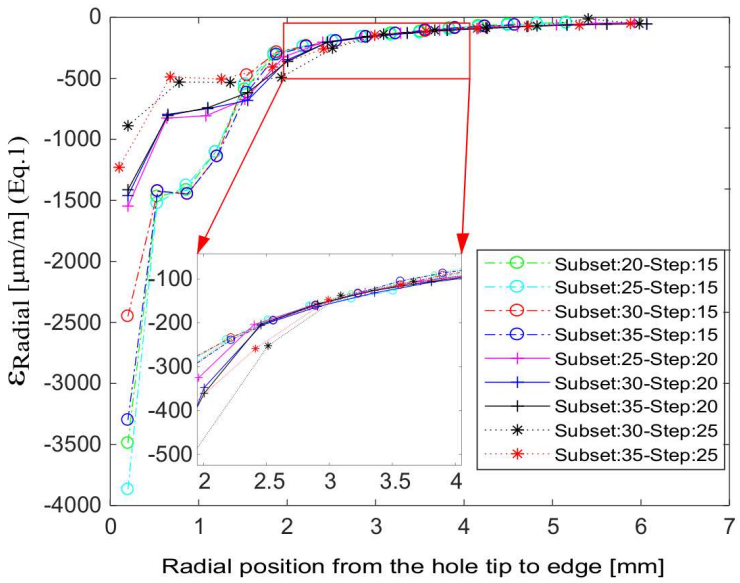

(a)
Strain Decay for $4 \mathrm{~mm}$ hole depth with DIC parameters

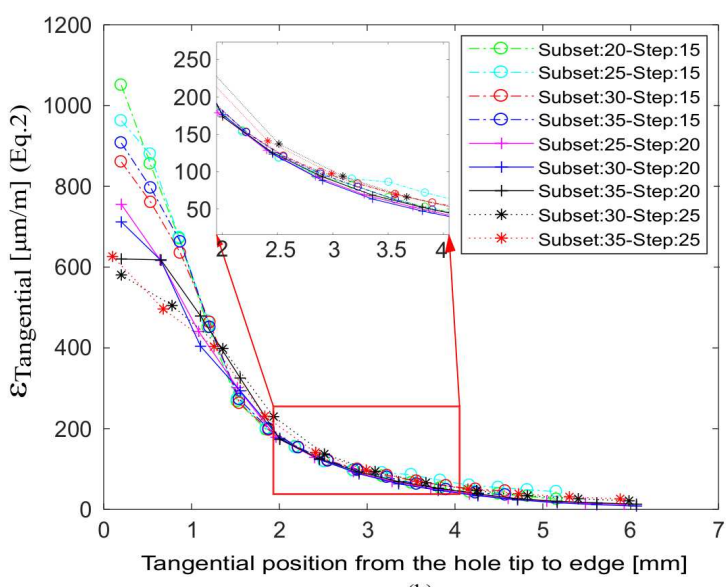

(b)

Figure 9: Experimental strain decay for different DIC parameters; $\varepsilon_{r}$ (a) and $\varepsilon_{t}$ (b). 


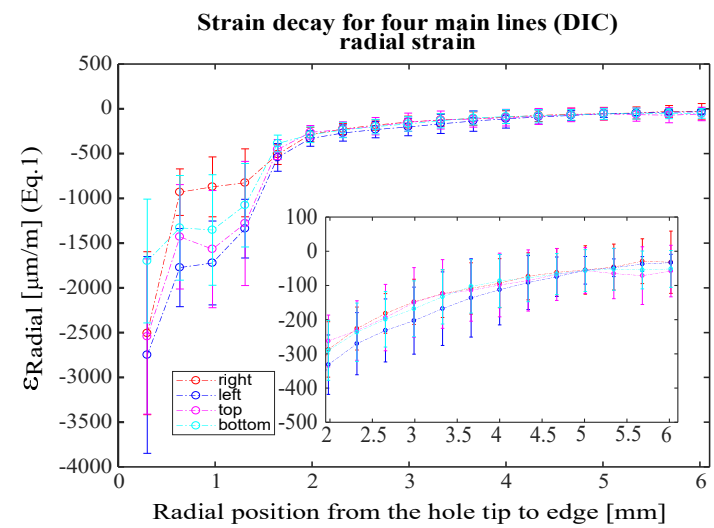

(a)

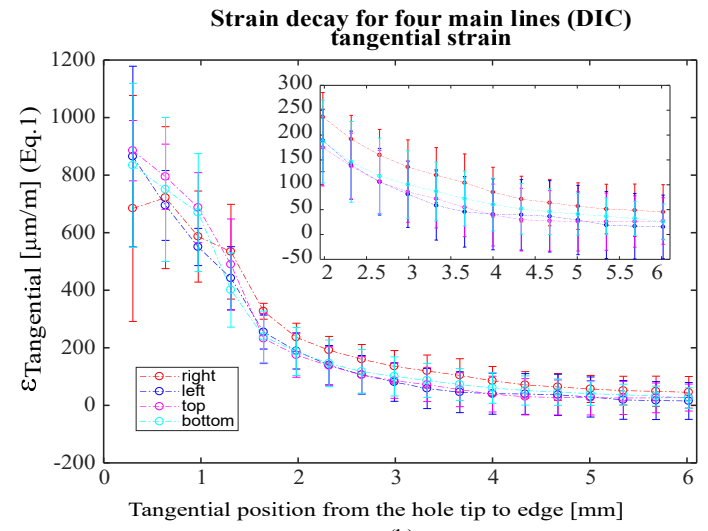

(b)

Figure 10: Average strain decay for four main lines; $\varepsilon_{r}$ (a) and $\varepsilon_{t}$ (b) (subset size:30, step size:15).

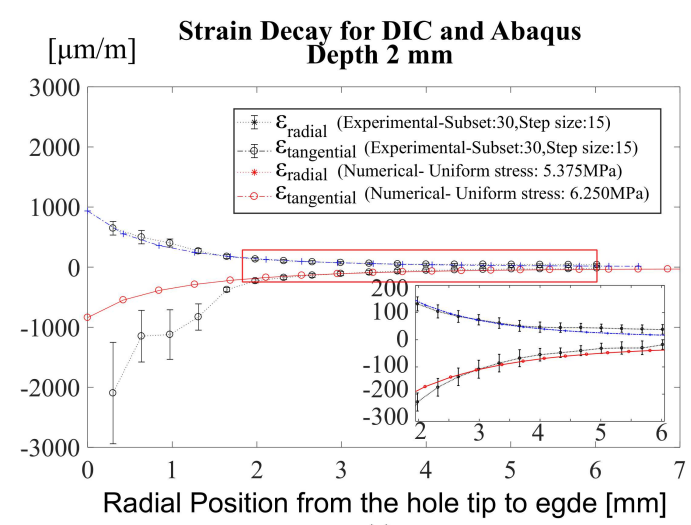

(a)

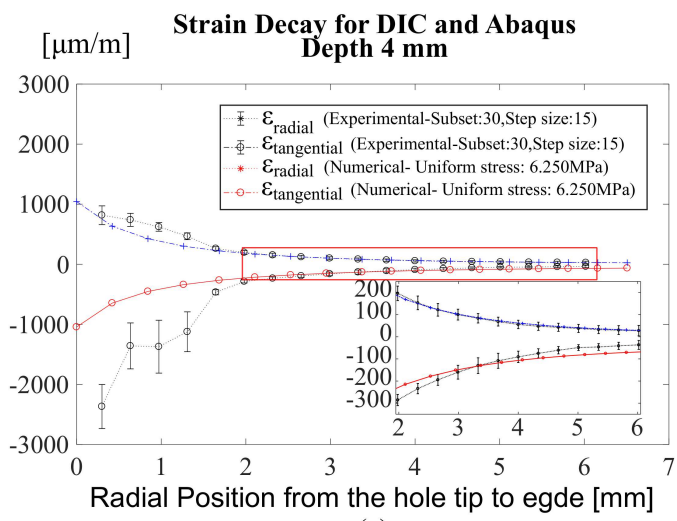

(c)

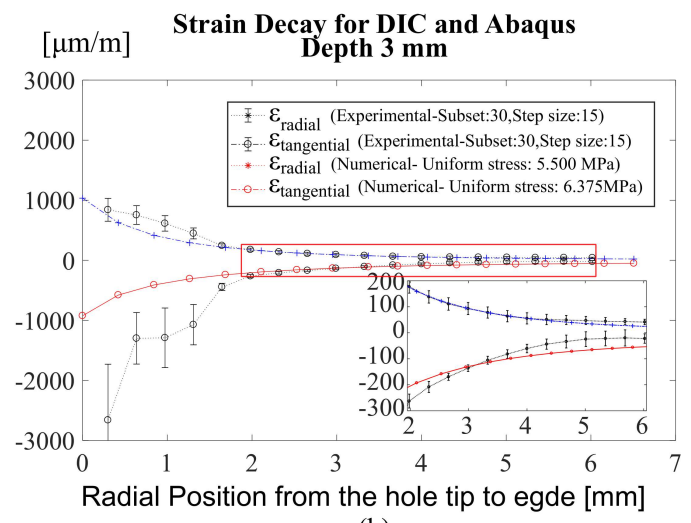

(b)

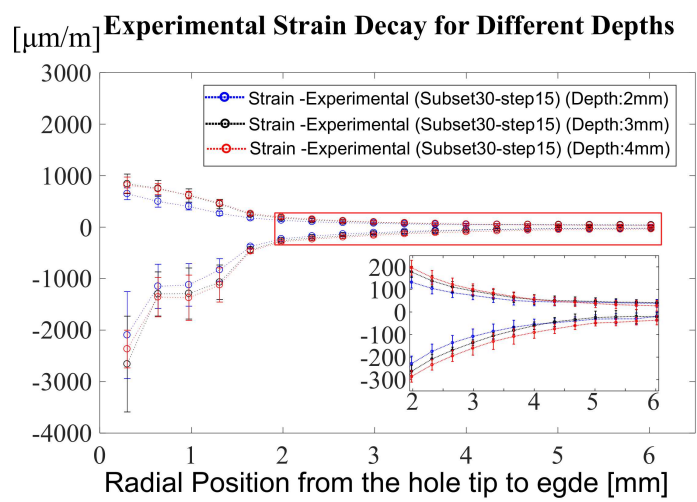

(d)

Figure 11: Strain decay taken from the DIC and the Abaqus with hole depth; 2mm (a), 3mm (b), 4mm (c) and the experimental decays for the three different depths $(\mathrm{d})$. 
Strain X

Hole Depth:2mm
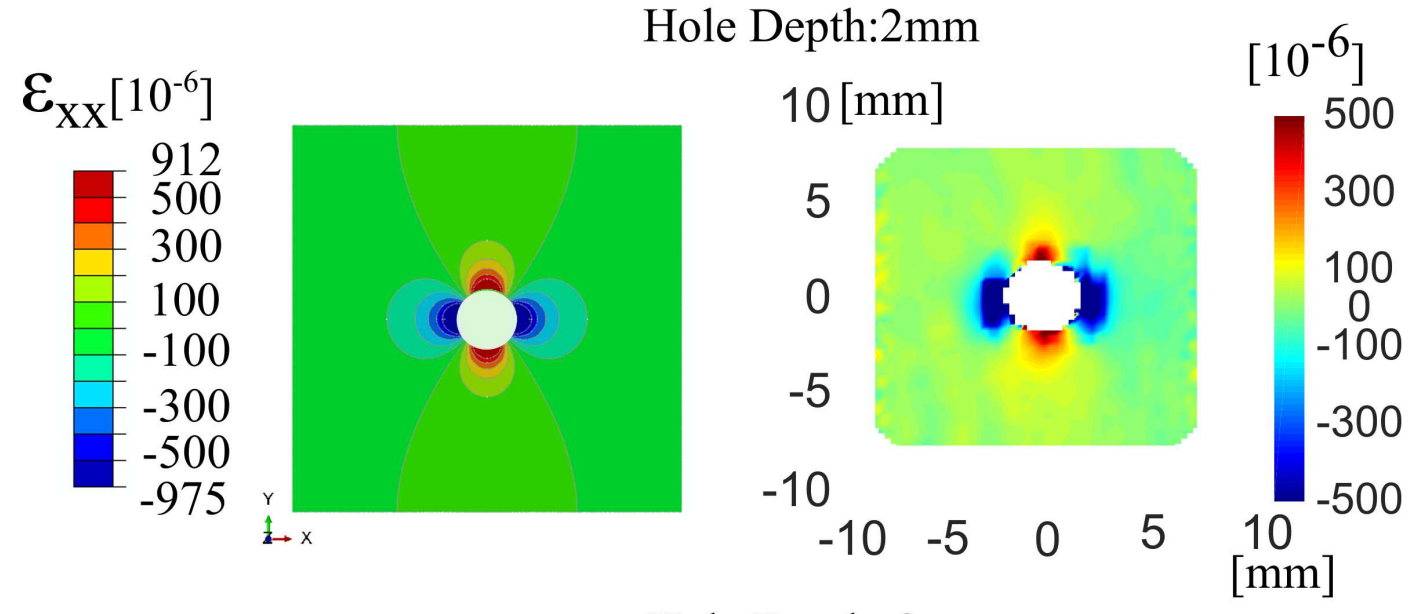

Hole Depth: $3 \mathrm{~mm}$

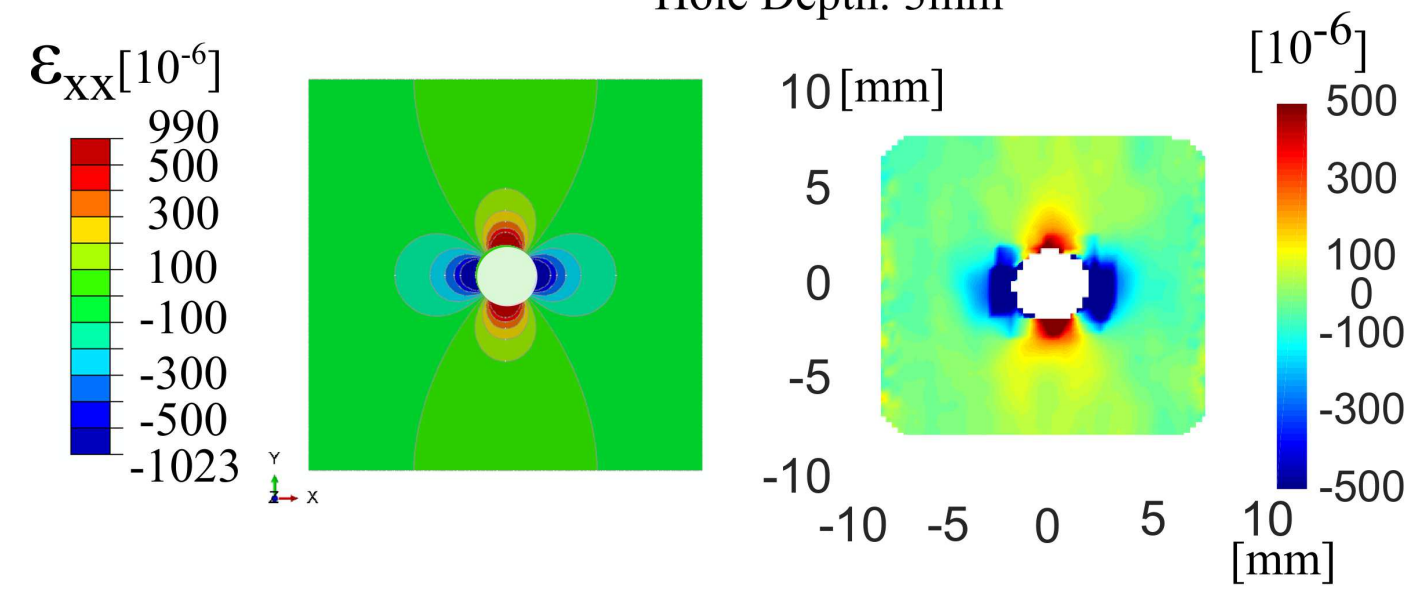

Hole Depth: $4 \mathrm{~mm}$
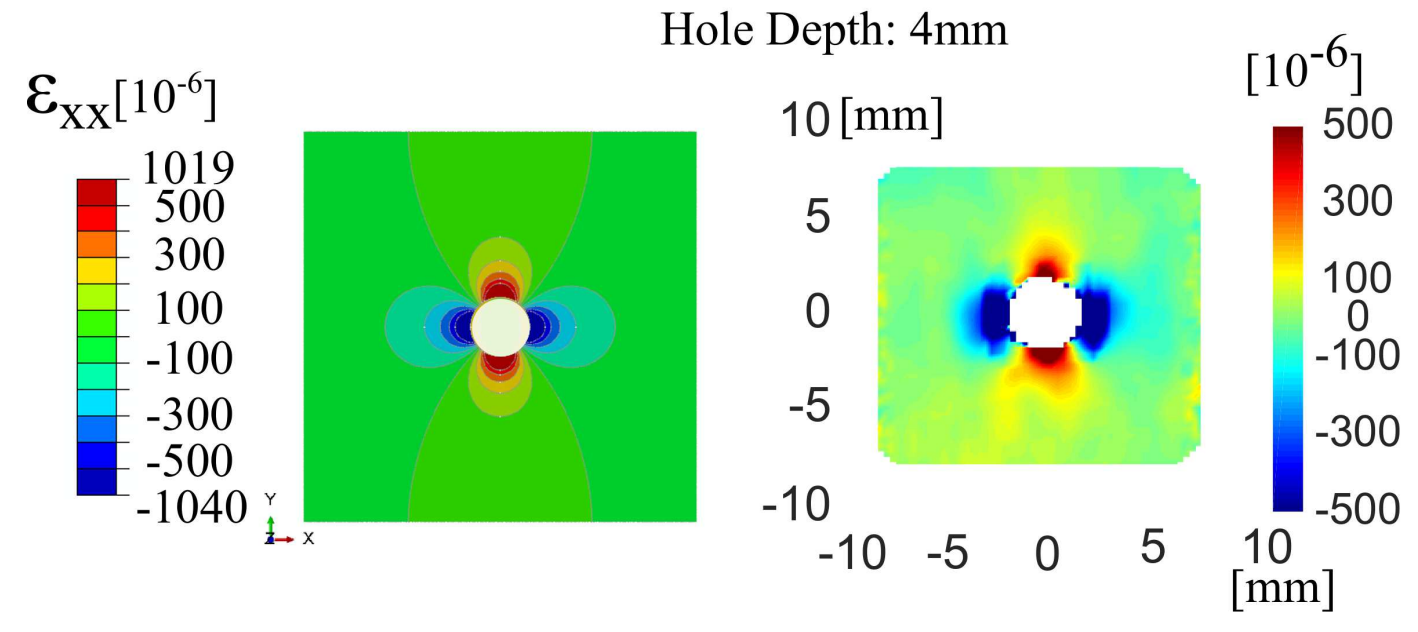

Figure 12: Numerical (left column) and the experimental (right column) strain fields for $2 \mathrm{~mm}, 3 \mathrm{~mm}$ and $4 \mathrm{~mm}$ hole depths. 
Table 1: An overview of the studies on residual stress measurement with DIC.

\begin{tabular}{|c|c|c|c|c|c|}
\hline Pultruded Profile & Material & $\begin{array}{c}\text { Reinforcement } \\
\text { Type }\end{array}$ & $\begin{array}{c}\text { Heater } \\
\text { Temperatures }\left[{ }^{\circ} \mathrm{C}\right]\end{array}$ & $\begin{array}{l}\text { Pulling Speed } \\
{[\mathrm{mm} / \mathrm{min}]}\end{array}$ & $\begin{array}{c}\text { Residual } \\
\text { Stress [MPa] }\end{array}$ \\
\hline $\begin{array}{c}\text { Flat Plate }[7] \\
(25.4 \mathrm{~mm} \text { thickness })\end{array}$ & Glass/Epoxy & UD & $171-188-188$ & 200 & 3.70 \\
\hline $\begin{array}{c}\text { Rod }[8] \\
(3 \mathrm{~mm} \text { thickness })\end{array}$ & Graphite/Epoxy & UD & Prescribed & 300 & 0.26 \\
\hline $\begin{array}{c}\text { Box }[9] \\
\text { (3 mm thickness) } \\
\text { L-shaped }[10]\end{array}$ & Glass/Polyester & $\mathrm{CFM}+\mathrm{UD}$ & $140-130$ & 650 & 10.70 \\
\hline $\begin{array}{l}\text { (5 mm thickness) } \\
\text { NACA0018 }[11]\end{array}$ & Glass/Polyester & $\mathrm{CFM}+\mathrm{UD}$ & $110-140$ & 600 & 5.12 \\
\hline $\begin{array}{l}\text { (18 mm thickness) } \\
\text { Square profile [12] }\end{array}$ & Glass/Epoxy & UD & $171-188-188$ & 200 & 3.67 \\
\hline (100 mm thickness) & Glass/Polyester & UD & $110-140$ & 100 & 6.92 \\
\hline
\end{tabular}

Table 2: An overview of the studies on residual stress measurement using DIC.

\begin{tabular}{|c|c|c|c|c|}
\hline & Material & Stress & Strain & STD \\
\hline Jakobsen $[36]$ & $\operatorname{Epoxy}(\mathrm{E}=2.9 \mathrm{GPa})$ & $4.39-5.38 \mathrm{MPa}$ & $500 \mu \mathrm{m} / \mathrm{m}$ & $0.46 \mathrm{MPa}(\mathrm{STD})$ \\
\hline Lord $[37]$ & $\operatorname{Aluminum}(\mathrm{E}=70 \mathrm{GPa})$ & $158 \mathrm{MPa}$ & $1.5-4.5 \mu \mathrm{m} / \mathrm{m}$ & $50 \mathrm{MPa}(\mathrm{STD})$ \\
\hline Harrington [38] & $\operatorname{Steel}(E=205 \mathrm{GPa})$ & $10 \mathrm{MPa}$ & - & 6MPa (STD) \\
\hline$M a[39]$ & $\operatorname{Steel}(\mathrm{E}=210 \mathrm{GPa})$ & $205 \mathrm{MPa}$ & - & $30 \mathrm{MPa}(\mathrm{STD})$ \\
\hline Baldi $[40]$ & $\operatorname{Aluminum}(\mathrm{E}=70 \mathrm{GPa})$ & $10 \mathrm{MPa}$ & - & $0.2 \mathrm{MPa}$ (Error) \\
\hline
\end{tabular}

Table 3: Effective properties for a UD polyester/glass fiber composite.

\begin{tabular}{l|ll}
$\left(\mathrm{V}_{\mathrm{f}}=0.463\right)$ & & \\
\hline & SCFM & Unit \\
\hline$E_{1}$ & 36.05 & $\mathrm{GPa}$ \\
$E_{2}=E_{3}$ & 8.70 & $\mathrm{GPa}$ \\
$G_{12}=G_{13}$ & 3.02 & $\mathrm{GPa}$ \\
$G_{23}$ & 2.80 & $\mathrm{GPa}$ \\
$\nu_{12}=\nu_{13}$ & 0.31 & - \\
$\nu_{23}=\nu_{32}$ & 0.56 & - \\
\hline
\end{tabular}


Table 4: Estimated noise for the case; specimens were stationary on the fixture. Mean values are tabulated with standard deviations in parentheses.

\begin{tabular}{cc|cc}
\hline & Step Size & 20 & 25 \\
Subset Size & & & \\
\hline 20 & $-4.9 \mu \mathrm{m} / \mathrm{m}(41.2 \mu \mathrm{m} / \mathrm{m})$ & & \\
25 & $-6.4 \mu \mathrm{m} / \mathrm{m}(36.4 \mu \mathrm{m} / \mathrm{m})$ & $-6.9 \mu \mathrm{m} / \mathrm{m}(21.7 \mu \mathrm{m} / \mathrm{m})$ & \\
30 & $-6.6 \mu \mathrm{m} / \mathrm{m}(33.7 \mu \mathrm{m} / \mathrm{m})$ & $-7.2 \mu \mathrm{m} / \mathrm{m}(20.2 \mu \mathrm{m} / \mathrm{m})$ & $-7.9 \mu \mathrm{m} / \mathrm{m}(14.2 \mu \mathrm{m} / \mathrm{m})$ \\
35 & $-5.9 \mu \mathrm{m} / \mathrm{m}(32.3 \mu \mathrm{m} / \mathrm{m})$ & $-7.1 \mu \mathrm{m} / \mathrm{m}(19.0 \mu \mathrm{m} / \mathrm{m})$ & $-6.4 \mu \mathrm{m} / \mathrm{m}(13.9 \mu \mathrm{m} / \mathrm{m})$ \\
\hline
\end{tabular}

Table 5: Estimated noise for the case; specimens were physically taken from the fixture and placed back to mimic the replacing after drilling. Mean values are tabulated with standard deviations in parentheses.

\begin{tabular}{c|ccc} 
& & & 2 \\
Subset Size & Step Size & 20 & 25 \\
\hline 20 & $-5.3 \mu \mathrm{m} / \mathrm{m}(42.7 \mu \mathrm{m} / \mathrm{m})$ & \\
25 & $-5.3 \mu \mathrm{m} / \mathrm{m}(38.8 \mu \mathrm{m} / \mathrm{m})$ & $-5.8 \mu \mathrm{m} / \mathrm{m}(25.4 \mu \mathrm{m} / \mathrm{m})$ & \\
30 & $-6.2 \mu \mathrm{m} / \mathrm{m}(36.8 \mu \mathrm{m} / \mathrm{m})$ & $-5.9 \mu \mathrm{m} / \mathrm{m}(24.3 \mu \mathrm{m} / \mathrm{m})$ & $-6.8 \mu \mathrm{m} / \mathrm{m}(17.1 \mu \mathrm{m} / \mathrm{m})$ \\
35 & $-5.8 \mu \mathrm{m} / \mathrm{m}(34.3 \mu \mathrm{m} / \mathrm{m})$ & $-5.9 \mu \mathrm{m} / \mathrm{m}(22.8 \mu \mathrm{m} / \mathrm{m})$ & $-6.7 \mu \mathrm{m} / \mathrm{m}(17.1 \mu \mathrm{m} / \mathrm{m})$ \\
\hline
\end{tabular}

Table 6: Estimated uniform stress values for different specimens and hole depths.

\begin{tabular}{c|ccccccc|c} 
Specimens & Units are & in [MPa & \multicolumn{7}{|c}{} & & \\
& $\begin{array}{c}\sigma_{\text {Based on }} \\
\text { Radial Strain }\end{array}$ & $\begin{array}{c}\sigma_{\text {Based on }} \\
\text { Radial Strain }\end{array}$ & $\begin{array}{c}\sigma_{\text {Based on }} \\
\text { Radial Strain }\end{array}$ & $\begin{array}{c}\sigma_{\text {Based on }} \\
\text { Tangential Strain }\end{array}$ & $\begin{array}{c}\sigma_{\text {Based on }} \\
\text { Tangential Strain }\end{array}$ & $\begin{array}{c}\sigma_{\text {Based on }} \\
\text { Tangential Strain }\end{array}$ & Average & STD \\
Depth & $(2 \mathrm{~mm})$ & $(3 \mathrm{~mm})$ & $(4 \mathrm{~mm})$ & $(2 \mathrm{~mm})$ & $(3 \mathrm{~mm})$ & $(4 \mathrm{~mm})$ & \\
\hline specimen 1 & 5.875 & 6.000 & 5.000 & 6.125 & 7.000 & 7.000 & 6.021 & 0.772 \\
specimen 2 & 7.125 & 5.625 & 6.000 & 6.125 & 7.375 & 5.750 & 6.333 & 0.672 \\
specimen 3 & 5.625 & 4.625 & 6.250 & 5.375 & 6.500 & 4.875 & 5.542 & 0.676 \\
specimen 4 & 4.750 & 6.000 & 5.250 & 7.125 & 5.750 & 5.125 & 5.667 & 0.769 \\
specimen 5 & 4.500 & 9.125 & 5.000 & 8.500 & 5.125 & 8.750 & 6.833 & 1.976 \\
\hline Average & 5.575 & 6.275 & 5.500 & 6.475 & 6.350 & 6.300 & & \\
STD & 0.931 & 1.511 & 0.524 & 1.213 & 0.819 & 1.429 & &
\end{tabular}

